\title{
Subcutaneous Administration of Monoclonal Antibodies in Oncology
}

\section{Subkutane Applikation monoklonaler Antikörper in der Onkologie}

Authors

Affiliations
C. Jackisch ${ }^{1}$, V. Müller ${ }^{2}$, C. Maintz ${ }^{3}$, S. Hell ${ }^{4}$, B. Ataseven

Obstetrics and Gynecology, Sanaklinikum Offenbach, Offenbach

${ }^{2}$ Klinik und Poliklinik für Gynäkologie, Universitätsklinikum Hamburg-Eppendorf, Hamburg

${ }^{3}$ Hämatologisch-Onkologische Praxis, Würselen

${ }^{4}$ Medizinisch-wissenschaftliche Beratung, Speyer

${ }^{5}$ Klinik für Gynäkologie \& Gynäkologische Onkologie, Kliniken Essen-Mitte, Essen

\section{Key words}

- monoclonal antibodies

- subcutaneous therapy

- breast cancer

- trastuzumab

- oncology

Schlüsselwörter

- monoklonale Antikörper

- subkutane Therapie

- Mammakarzinom

- Trastuzumab

- Onkologie

Deutschsprachige Zusatzinformationen online abrufbar unter: www.thieme-connect.de/ ejournals/toc/gebfra

\section{received $\quad 5.12 .2013$ \\ revised 20.1.2014 \\ accepted 2.2.2014}

\section{Bibliography}

DOI http://dx.doi.org/ 10.1055/s-0034-1368173

Geburtsh Frauenheilk 2014; 74: 343-349 @ Georg Thieme Verlag KG Stuttgart · New York . ISSN 0016-5751

\section{Correspondence}

Prof. Dr. Christian Jackisch

Sanaklinikum Offenbach Obstetrics and Gynecology Starkenburgring 66

63069 Offenbach

christian.jackisch@sana.de

\section{Abstract \\ $\nabla$}

Treatment with monoclonal antibodies (mabs) has become an established component of oncological therapy. The monoclonal antibodies available for this purpose are mainly administered intravenously in individually adapted doses according to body weight over longer treatment times. For other chronic diseases such as, for example, diabetes mellitus, the subcutaneous administration of drugs is an established therapy option. For the subcutaneous administration of larger volumes as needed for mab solutions the extracellular matrix of the subcutaneous tissue represents a problem. The co-formulation with recombinant human hyaluronidase makes the relatively painfree administration of larger fluid volumes and thus the subcutaneous administration of monoclonal antibodies possible, as illustrated by the development of a subcutaneous formulation of trastuzumab. This constitutes a less invasive, time-optimised and flexible form of administration for patients with HER2-positive breast cancer that, with its fixed dosing possibilities, contributes to therapeutic safety. The example of trastuzumab shows that the subcutaneous administration of monoclonal antibodies can simplify oncological long-term therapy not only for the patients but also for the medical personnel.

\section{Introduction}

In the advanced stages of numerous tumour entities, the optimisation of oncological therapy leads to a marked prolongation of survival. Thus, the chronic stage of the disease acquires a completely different relevance. According to data of the German Cancer Society (Deutsche Krebsgesellschaft) $81 \%$ of the patients are still alive 5 years after the

\section{Zusammenfassung \\ $\nabla$}

Die Behandlung mit monoklonalen Antikörpern (mAK) ist ein fester Bestandteil der onkologischen Therapie geworden. Die dafür zur Verfügung stehenden monoklonalen Antikörper werden überwiegend intravenös, individualisiert gewichtsadaptiert und über längere Behandlungszeiträume verabreicht. Bei anderen chronischen Erkrankungen wie beispielsweise Diabetes mellitus stellt die subkutane Applikation von Medikamenten, eine etablierte Therapieform dar. Für die subkutane Applikation größerer Volumina stellt die Physiologie der extrazellulären Matrix des subkutanen Gewebes ein Hindernis dar, wie sie für die Lösung mAK erforderlich ist. Die Koformulierung mit rekombinanter humaner Hyaluronidase ermöglicht die schmerzarme Gabe größerer Volumina und damit die subkutane Applikation von monoklonalen Antikörpern, wie die Entwicklung einer subkutanen Formulierung für Trastuzumab zeigt. Mit dieser steht Patientinnen mit HER2-positivem Mammakarzinom eine weniger invasive, zeitoptimierte und flexiblere Applikationsform zur Verfügung, die mit einer fixen Dosierungsmöglichkeit zur Therapiesicherheit beiträgt. Das Beispiel Trastuzumab zeigt, dass die subkutane Verabreichung monoklonaler Antikörper die onkologische Langzeittherapie sowohl für Patienten als auch für medizinisches Fachpersonal vereinfachen könnte.

first diagnosis of breast cancer. Of those patients with advanced breast cancer, about one third are still alive 5 years after the first occurrence of metastases and one in ten of the afflicted patients survives for more than 10 years [1].

Monoclonal antibodies today are an established component of oncological therapy. They are mainly administered intravenously over longer treatment times of up to several years. For onco- 
Table 1 Advantages and disadvantages of subcutaneous and intravenous administration.

\begin{tabular}{|c|c|c|}
\hline Administration form & Advantages & Challenges \\
\hline s.c. & $\begin{array}{l}\text { shorter clinic/office visits for the patient } \\
\text { optimised use of resources } \\
\text { - self-administration is possible } \\
\text { - less invasive than i.v. administration }\end{array}$ & $\begin{array}{l}\text { pain-free administration of larger fluid volumes } \\
\text { - minimisation of adverse events at the injection site } \\
\text { guarantee of good absorption and bioavailability } \\
\text { - administration of exact doses requires practice }\end{array}$ \\
\hline i.v. & $\begin{array}{l}\text { suitable for substances that can cause irritations } \\
\text { voitable for drugs that must be administered in larger } \\
\text { volumes }\end{array}$ & $\begin{array}{l}\text { - requires trained personnel in special infusion settings } \\
\text { - handling of port system (e.g., central port, Hickman catheter, } \\
\text { PICC) } \\
\text { - placement of a peripheral cannula } \\
\text { - longer clinic/office stays than with s.c. administration } \\
\text { - risk of systemic infections }\end{array}$ \\
\hline
\end{tabular}

logical therapy with mabs, a less invasive, appreciably less timeconsuming and more flexible form of administration, as represented by subcutaneous administration, results in a significant improvement in quality of life for the patients who, in this stage of the disease, have often returned to their daily routine of life. They must spend less time as patients in treatment centres and can use the thus gained time for personal purposes and can benefit from a previously not known social independence. The subcutaneous route of administration simplifies the therapy with monoclonal antibodies not only for the patient but also for the medical personnel ( Table 1). Ultimately, self-administration at home may become feasible.

\section{Material and Methods}

This article is based on literature searches on the use of monoclonal antibodies in oncological clinical entities in PubMed, MEDLINE, Clinicaltrials.gov and evaluation reports of the European Medical Agency (EMA) without limitation of the search period as well as a selective search of congress abstracts of the Annual Meetings of the American Society of Clinical Oncology (ASCO), Annual Meetings of the American Society of Hematology (ASH), the San Antonio Breast Cancer Symposia, the St. Gallen Breast Cancer Conferences up to and including 2009. In addition several review articles and their reference lists were evaluated.

\section{Data on subcutaneous administration of} monoclonal antibodies from oncological trials

The PubMed search (search item [antibody or antibodies] and monoclonal and cancer and subcutaneous, no limitation of search period) provided, after evaluation of the abstracts of all 945 hits and a subsequent targeted search for the previously identified antibodies, 70 publications in which the subcutaneous administration of monoclonal antibodies as oncological therapeutics in humans was reported (alemtuzumab $\times 33$, denosumab $\times 30$, trastuzumab $\times 1$, rituximab $\times 1$, veltuzumab $\times 1$, abagovomab $\times 4)$.

Veltuzumab, an antibody directed against CD20, and abagovomab, a monoclonal murine antibody directed against CA125, are still undergoing clinical development.

For alemtuzumab (MabCampath ${ }^{\circledR}$ ), an antibody directed against CD52, studies have pointed to a comparable efficacy for intravenous and subcutaneous administrations [2,3]. However, alemtuzumab up to its withdrawal from the market in 2012 by the manufacturer Genzyme on the basis of its clinical development as a drug for patients with multiple sclerosis was only approved for intravenous use in patients with chronic lymphatic leukaemia [4].

For rituximab (MabThera ${ }^{\circledR}$ ), the first therapeutic antibody against the CD20 antigen on the surface of normal and malignant $B$ cells, a subcutaneous administration form is currently under development $[5,6]$. The subcutaneous administration form of trastuzumab (Herceptin ${ }^{\circledR}$ ), an antibody targeted against HER2 as therapy for HER2-positive metastatic and early breast cancer as well as HER2-positive metastatic gastric cancer was approved for use as therapy for patients with HER2-positive breast cancer by the European Drug Authority in August 2013 [7].

Denosumab $\left(\mathrm{Xgeva}^{\circledR}\right)$, an antibody against RANK-L for the reduction of bone-related complications in patients with an osseous metastatic solid tumour, has been developed consequently as an antibody for subcutaneous administration. Its approval was based on the significant reduction of the risk for skeletal-related events in comparison with zolendronate therapy in three large phase III studies, one of which involved 2046 patients with advanced breast cancer [8], one with 1901 patients suffering from castration-resistant prostate cancer [9] and one with 1776 patients having various solid tumour entities (with the exception of breast and prostate cancer) and multiple myelomas [10]. In a further placebo-controlled trial with 1432 patients suffering from castration-resistant prostate cancer a significant prolongation of the bone metastasis-free survival and a significant delay in the occurrence of bone metastases was achieved with denosumab [11].

The question arises as to why subcutaneous administration forms are scarcely available to patients ( Table 2 ) although therapy with monoclonal antibodies over longer periods of time has developed to become a cornerstone of modern oncological therapy. The challenges for the development of alternative subcutaneous formulations can be nicely illustrated for the example of trastuzumab.

\section{Therapy with trastuzumab for patients with HER2-positive breast cancer}

Therapy with trastuzumab, a monoclonal antibody against the human epidermal growth factor receptor HER2, is nowadays the standard for treatment of HER2-positive breast cancer [12-14] and has appreciably improved the prognosis for patients not only in the early stages but also of those in a metastatic situation [ 15 , 16].

Patients with early breast cancer receive trastuzumab as an adjuvant therapy every three weeks for a total of 12 months. Patients with metastatic breast cancer receive trastuzumab as a rule up to progression or even beyond as "treatment beyond progression". 
Table 2 Monoclonal antibodies with clinical data on subcutaneous administration as oncological therapeutic agents.

\begin{tabular}{|c|c|c|}
\hline Name & Antibody & Approval status as oncological therapeutic agent \\
\hline Abagovomab & $\begin{array}{l}\text { murine monoclonal antibody } \\
\text { against CA125 }\end{array}$ & In clinical development for subcutaneous administration in ovarian cancer. \\
\hline Veltuzumab & $\begin{array}{l}\text { humanised monoclonal antibody } \\
\text { against CD20 }\end{array}$ & In clinical development for subcutaneous administration in non-Hodgkin's lymphoma. \\
\hline $\begin{array}{l}\text { Alemtuzumab } \\
\left.\text { (MabCampath }^{\circledR}\right)\end{array}$ & $\begin{array}{l}\text { humanised antibody } \\
\text { against CD52 }\end{array}$ & $\begin{array}{l}\text { Approved up to August } 2012 \text { as intravenous therapy for chronic lymphatic leukaemia, } \\
\text { withdrawn from the market due to clinical development as therapy for multiple sclerosis. }\end{array}$ \\
\hline $\begin{array}{l}\text { Rituximab } \\
\left(\text { MabThera }{ }^{\circledR}\right)\end{array}$ & $\begin{array}{l}\text { chimeric (murine/human) } \\
\text { monoclonal antibody } \\
\text { against CD20 }\end{array}$ & $\begin{array}{l}\text { Approved as intravenous therapy for follicular lymphoma (after induction chemo- } \\
\text { therapy and refractory disease to or recurrence after chemotherapy), CD20-positive } \\
\text { diffuse large-cell B-cell non-Hodgkin lymphoma, chronic lymphatic leukaemia } \\
\text { (not pre-treated and recurrent/refractory). }\end{array}$ \\
\hline $\begin{array}{l}\text { Trastuzumab } \\
\left(\text { Herceptin }^{\circledR}\right)\end{array}$ & $\begin{array}{l}\text { humanised monoclonal antibody } \\
\text { against HER2 }\end{array}$ & $\begin{array}{l}\text { Approved as intravenous therapy for HER2-positive metastatic breast cancer, } \\
\text { HER2-positive early breast cancer, HER2-positive metastatic gastric cancer. } \\
\text { Approved as subcutaneous therapy for HER2-positive breast cancer. }\end{array}$ \\
\hline $\begin{array}{l}\text { Denosumab } \\
\left(\text { Xgeva }^{\circledR}\right)\end{array}$ & $\begin{array}{l}\text { human monoclonal antibody } \\
\text { against RANK ligand }\end{array}$ & $\begin{array}{l}\text { Approved as subcutaneous therapy to prevent bone-related complications } \\
\text { of solid tumours and bone involvement. }\end{array}$ \\
\hline
\end{tabular}

For the add-on administration of trastuzumab to a standard chemotherapy, randomised phase III trials have reported median progression-free intervals of from 7.1 months [17] up to 11.1 months [18], and in randomised phase II trials of up to 18.6 months [19]. According to the therapy recommendations of the Organ Commission Mamma of the "Arbeitsgemeinschaft Gynäkologische Onkologie (AGO)" and the European Society of Medical Oncology (ESMO) therapy with trastuzumab may also be continued beyond progression, i.e., altogether for a longer period of time $[13,14]$.

To date trastuzumab is exclusively administered by the intravenous route. According to the valid scientific information that is based on the results of the approval studies, the duration of infusion for the first dose amounts to 90 minutes with a follow-up observation time of 6 hours from the start of the infusion, the subsequent infusions then require 30 minutes with a follow-up observation period of 2 hours from the start of the infusion [20]. In clinical routine, however, the actual infusion times will be longer or shorter than those mentioned above. As a rule intravenous therapy in the chronic disease phase is associated with a not inconsiderable expenditure of time in comparison with the actual duration of the therapy.

\section{Injection volumes and the extracellular matrix of subcutaneous tissue}

The monoclonal antibody denosumab is administered every 4 weeks as a subcutaneous injection at a dose of $120 \mathrm{mg}$ in an injection volume of $1.7 \mathrm{~mL}$ [21]. However, the dissolution of monoclonal antibodies usually requires larger injection volumes. Accordingly, the injection volumes of reconstituted solutions of trastuzumab at a dose of $6 \mathrm{mg} / \mathrm{kg}$ for a patient with a body weight of $70 \mathrm{~kg}$ amount to $20 \mathrm{~mL}$ for intravenous administration. A higher concentration of the solution and thus a reduction of the injection volume are only possible to a minor extent. Even at the maximum possible concentration for the injection solution of trastuzumab of $120 \mathrm{mg} / \mathrm{mL}$ [22] instead of the usual $21 \mathrm{mg} / \mathrm{mL}$ the required injection volume is still markedly in excess of $2 \mathrm{~mL}$

The extracellular matrix of the subcutaneous tissue limits the injection of larger volumes (>1-2 mL). The EM is a structural network of fibre proteins such as collagen and elastin in a viscoelastic gel consisting of hyaluronic acid and other glycosaminoglycans, complex linear polysaccharides. This network is important for the specific tissue architecture and controls the diffusion and flow of molecules. Collagen and hyaluronic acid form the decisive barrier to larger volumes ( Fig. 1) [23]. The injection of volumes larger than $2 \mathrm{~mL}$ is painful for the patient. In addition, larger molecules such as, e.g., proteins can be held back in the tissue due to the viscosity of the extracellular matrix. This can result in the local degradation of these substances, local reactions at the injection site and a lower bioavailability [23]. The physiology of the extracellular matrix of subcutaneous tissue thus constitutes a barrier especially for the subcutaneous administration of monoclonal antibodies.

In the case of trastuzumab a problem-free and painless subcutaneous administration can be achieved with the ENHANZE ${ }^{\mathrm{TM}}$ technology that is described below.

\section{Coformulation with recombinant hyaluronidase}

The half-life of hyaluronic acid amounts to 15-20 hours. It is subject to hydrolytic degradation by the enzyme hyaluronidase. To overcome the volume limitations due to the extracellular matrix a coformulation of trastuzumab with recombinant hyaluronidase (rHuPH20) was chosen for subcutaneous administration. This enzyme effects a reversible hydrolysis of hyaluronic acid and thus reduces the viscosity of the gel-like extracellular matrix. This leads to an increase in permeability. The subcutaneous dispersion area increases and permits the administration of larger fluid volumes. On account of the half-life of hyaluronic acid these structural changes in the extracellular matrix are only temporary $[23,24]$. The human PH-20 gene codes for a hyaluronidase that is active at neutral $\mathrm{pH}$, and degrades glycosaminoglycans under physiological conditions. Cloning of the cDNA of the soluble domain of this human $\mathrm{PH}-20$ hyaluronidase makes possible the recombinant preparation of a glycosylated enzyme in a purified, homogeneous formulation with a high specific activity. Molecules with a size of up to $200 \mathrm{~nm}$ are uniformly distributed upon co-injection with rHuPH20 and exhibit a significantly higher bioavailability, similar to that achieved with intravenous administration $[23,25,26]$.

\section{Dose finding for subcutaneous trastuzumab}

An alternative subcutaneous route for administration of a drug must provide a comparable efficacy, pharmacokinetics and safety in comparison with its established intravenous formulation. In a 


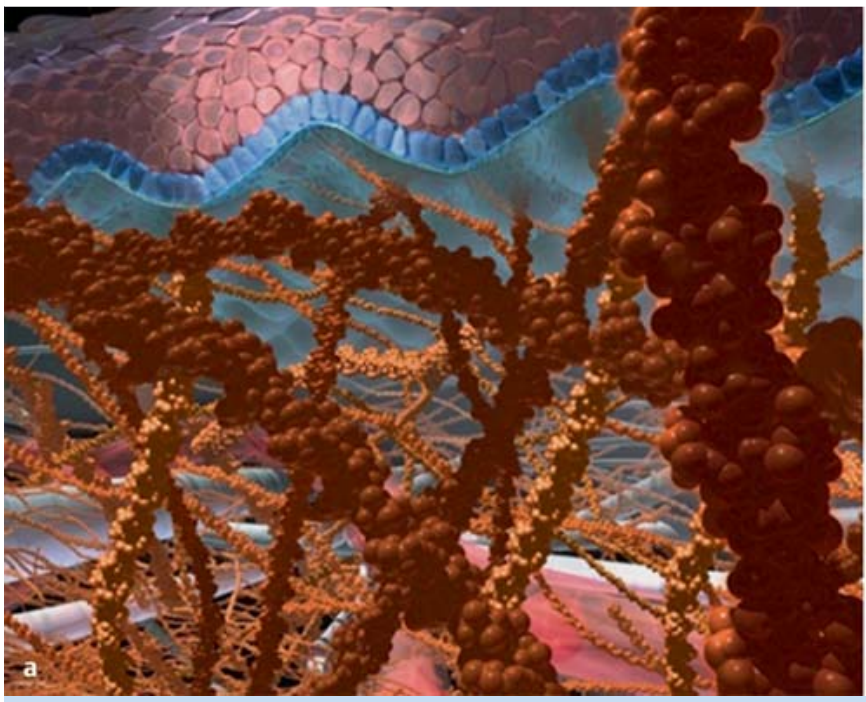

Fig. $1 \mathbf{a}$ and $\mathbf{b}$ Principle of subcutaneous administration using recombinant human hyaluronidase as carrier. a The subcutaneous tissue with its matrix of hyaluronic acid and collagen fibres limits the subcutaneous administration to volumes $<2 \mathrm{~mL}$. $\mathbf{b}$ The temporary and local degradation of hyaluronic acid

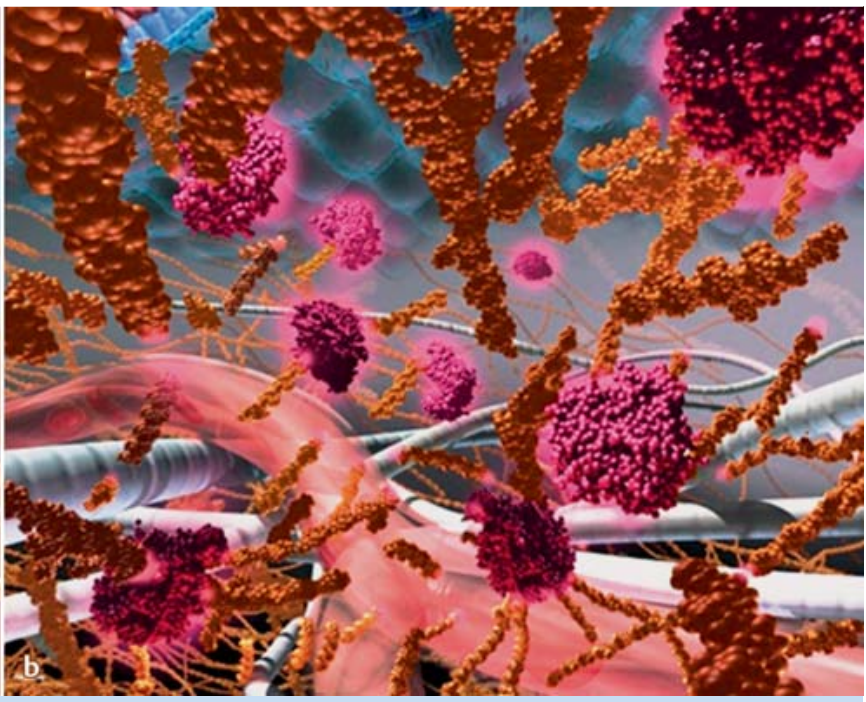

by recombinant human hyaluronidase leads to a temporary increase in the subcutaneous dispersion surface and makes possible the administration of larger fluid volumes (source: Hoffmann-La Roche).

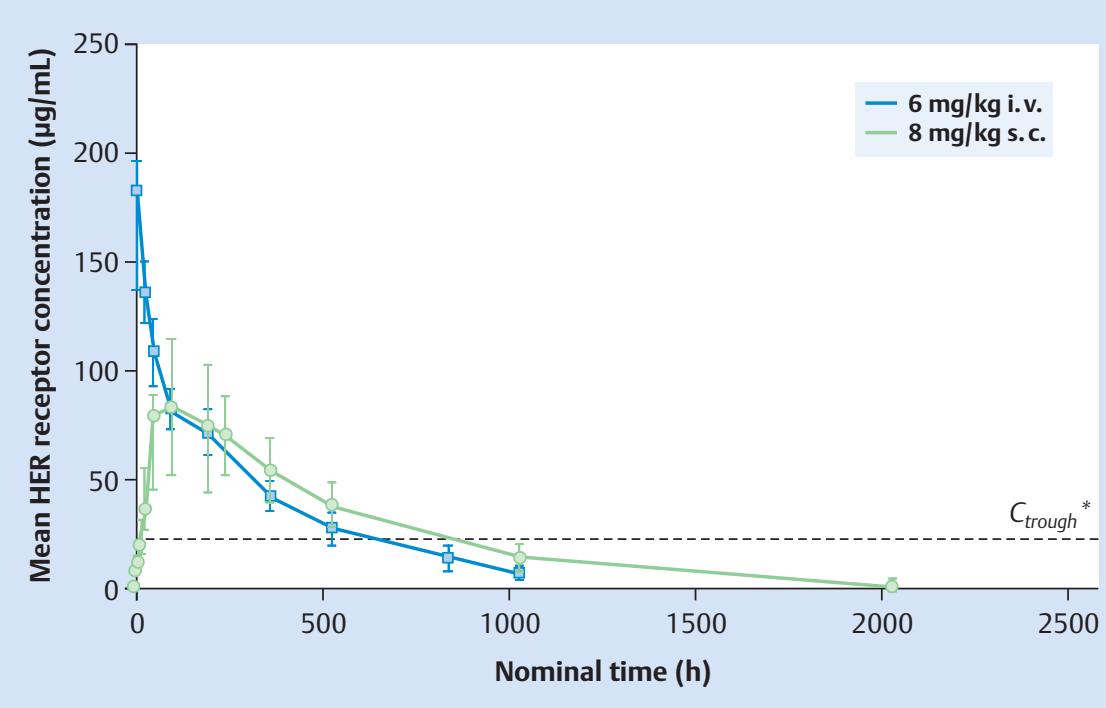

Fig. 2 Trastuzumab exposure in patients with HER2-positive early breast cancer for the doses $8 \mathrm{mg} / \mathrm{kg}$ s.c. and $6 \mathrm{mg} / \mathrm{kg}$ i. v. (after Wynne et al. [27]). * The $C_{\text {trough }}$ of $20 \mu \mathrm{g} / \mathrm{mL}$ reflects the target value established in preclinical xenograft models.

dose-finding trial with healthy male subjects and patients with HER2-positive breast cancer it was found that the dose of trastuzumab $8 \mathrm{mg} / \mathrm{kg}$ s.c. every 3 weeks provided a comparable exposure as the 3-weekly administration of $6 \mathrm{mg} / \mathrm{kg}$ trastuzumab i.v. (ه Fig. 2). Thus, the minimal or trough concentrations were reached immediately prior to the next administration of trastuzumab $\left(C_{\text {trough }}\right)$ which were at least as high as those after intravenous administration [27].

\section{Development of a fixed dose for trastuzumab}

In order to achieve the easiest possible handling and to assure a reduction in the sources of error such as wrong doses, a fixed dose irrespective of body weight for the subcutaneous administration of trastuzumab was sought after. The basic principle for the efficacy of trastuzumab is a saturation of the receptors which requires a minimum concentration of trastuzumab in serum. In order to maintain the efficacy of trastuzumab the serum concen- tration required for saturation of the receptors must be continuously held above a minimum level $[22,28]$. With the intravenous administration of trastuzumab this receptor saturation can be achieved more rapidly with higher initial doses [22]. Also with a fixed dose a saturation of the receptors should be assured from the 1st cycle onwards. The pharmacokinetic parameters for the various subcutaneous doses of trastuzumab were calculated with the help of various model simulations in which the data from the previously described dose-finding trials were incorporated. In this way, with a fixed dose of $600 \mathrm{mg}$ s.c., a similar $\mathrm{C}_{\text {trough }}$ and an at least equivalent exposure to trastuzumab over the dosing interval $\left(\mathrm{AUC}_{\mathrm{tau}}\right)$ were achieved as with the usual 3-weekly and weekly i.v. usage of trastuzumab with higher initial doses. An adequate receptor saturation with a fixed dose of $600 \mathrm{mg}$ s.c. is already reached even in the 1 st cycle $[22,29]$. 

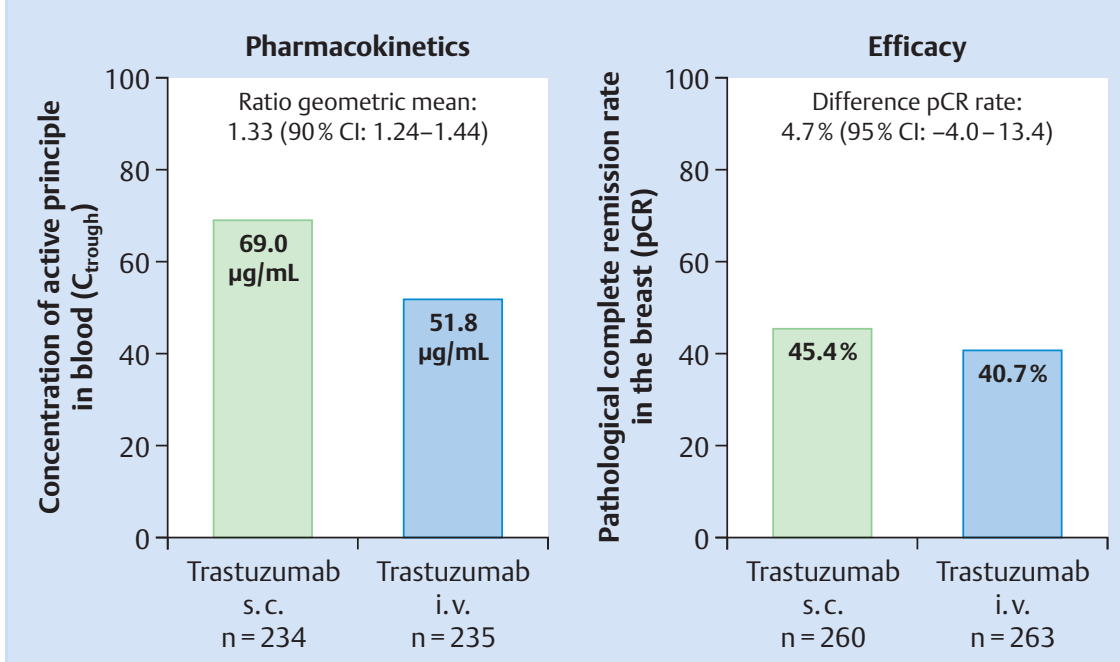

Fig. 3 Results for the co-primary endpoints for trastuzumab s. c. vs. i.v. in the HannaH trial (after Ismael et al. [30]).

\section{Randomised comparison of pharmacokinetics and efficacy}

The subcutaneous administration of the fixed dose of $600 \mathrm{mg}$ trastuzumab in $5 \mathrm{~mL}$ injection volume (trastuzumab $120 \mathrm{mg} / \mathrm{mL}$, rHuPH20 $2000 \mathrm{U} / \mathrm{mL}$ ) can be performed within 2-5 minutes. In the HannaH trial, a randomised open phase III study on 596 patients with HER2-positive early advanced or inflammatory breast cancer, this dose was compared with the established intravenous administration [30]. The patients received a neoadjuvant chemotherapy of 4 cycles of docetaxel $\left(75 \mathrm{mg} / \mathrm{m}^{2} ; \mathrm{q} 3 \mathrm{w}\right)$ and 4 cycles of FEC (fluorouracil $500 \mathrm{mg} / \mathrm{m}^{2}$, epirubicin $75 \mathrm{mg} / \mathrm{m}^{2}$, cyclophosphamide $500 \mathrm{mg} / \mathrm{m}^{2} ; \mathrm{q} 3 \mathrm{w}$ ). In addition trastuzumab was administered every 3 weeks either in the fixed dose of $600 \mathrm{mg}$ subcutaneous $(n=297)$ or intravenous $(8 \mathrm{mg} / \mathrm{kg}$ initial dose, $6 \mathrm{mg} / \mathrm{kg}$ maintenance dose $)(n=299)$. The therapy with trastuzumab was continued after surgery through to completion of 18 cycles.

For both administration forms of trastuzumab, the study revealed similar pharmacokinetics and comparable efficacies. The geometric mean of the trough concentration $\mathrm{C}_{\text {trough }}$ amounted to $69.0 \mu \mathrm{g} / \mathrm{mL}$ in the group with subcutaneous administration, and $51.8 \mu \mathrm{g} / \mathrm{mL}$ in the intravenous group. At 1.33 (90\% confidence interval 1.24-1.44) the ratio of the two values was above the previously defined non-inferiority limit of 0.80 ( $\odot$ Fig. 3 ).

$45.4 \%$ of the patients in the s.c. group and $40.7 \%$ of those in the i.v. group had a pathological complete remission (pCR). The difference between the two groups of $4.7 \%$ ( $95 \%$ confidence interval $-4.0-13.4$ ) in favour of trastuzumab s.c. was thus clearly above the non-inferiority limit of $-12.5 \%$ ( $\odot$ Fig. 3 ).

The incidence of adverse events of degrees 3-5 was similar in both groups. However, with $21 \%$ there were more severe adverse events (SAEs) in the s.c. group as compared with $12 \%$ in the i.v. group. This difference was mainly due to the differing frequencies of SAEs in the category infection: $8.1 \%$ in the s.c. group versus $4.4 \%$ in the i.v. group. The remaining SAEs showed similar distribution patterns and comparable frequencies over the different organ categories. The authors analysed these results and came to the conclusion that the trial physicians in this non-blinded study presumably followed a conservative policy with regard to the experimental subcutaneous administration and thus more frequently admitted these patients to hospital. Altogether, the safety profiles of the fixed subcutaneous dose and the established intravenous administration were comparable [30]. For the fixed dose there was no correlation between body weight and efficacy or side effects [31].

\section{Assessment of the preferences of patients and specialist medical personnel}

Ultimately, the development of a subcutaneous formulation is only justifiable when in clinical routine it is considered by the patients to really be a simpler and a more comfortable alternative to intravenous administration. For the subcutaneous administration of trastuzumab this was prospectively examined in the PrefHer trial (PrefHer, registered on clinical.trials.gov under NCT01401166), which systematically evaluated not only the preferences of the patients but also the satisfaction of the medical personnel with the subcutaneous administration form in comparison with the intravenous administration. Administration with the help of disposable syringes as well as the expenditure of time and costs of the alternative administration form were also taken into account. The results demonstrated a convincing preference of the patients for the subcutaneous administration of trastuzumab. Accordingly, 216 (91.5\%) of the patients preferred the subcutaneous over the intravenous administration (95\% confidence interval 87.2-94.7\%; $p<0.0001$ ). The most important reason mentioned was the time saving followed by less pain due to the subcutaneous administration [32]. Indeed, the effective treatment time for the patients and the time expenditure by the medical personnel were lower for the subcutaneous administration (6.8\%, 95\% CI 3.9-10.8). The most frequent reasons mentioned were fewer reactions at the infusion site in the sense of less pain, haemorrhagic rashes and irritations. The treatment environment was mentioned as reason twice [32]. During the crossover phase in this trial $6(2.5 \%)$ SAEs were reported. No relationship with the study medication was given for any of them [33]. The safety of trastuzumab s.c. is currently being evaluated in a large global trial (SafeHer, registered on clinical.trials.gov under NCT01566721) with 2500 patients in parallel in 2 cohorts for injection by syringe and by disposable syringe by the patients themselves in the adjuvant treatment situation. 


\section{Classification of the data on subcutaneous} administration of trastuzumab

For the example of trastuzumab it has been shown that, by means of a co-formulation with recombinant human hyaluronidase, a subcutaneous administration form that is also suitable for larger injection volumes with good bioavailability and comparable efficacy as for intravenous administration can be realised safely and effectively. The alternative subcutaneous administration of trastuzumab in a fixed dose of $600 \mathrm{mg}$ s.c. over 5 minutes has shown, in a randomised comparison with the established intravenous administration, similar pharmacokinetics, efficacy and safety and was even preferred by the patients due to the resulting saving in time and its less invasive nature. This was also accompanied by a shorter time expenditure for the medical personnel. The development of alternative subcutaneous administration formulations for long-term oncological therapy with monoclonal antibodies represents an as yet insufficiently exploited factor for cancer patients. In the patient's best interests, more intensive efforts should be undertaken to make further subcutaneous formulations of monoclonal antibodies available on the market. They could then make a valuable contribution to a higher quality of life for the longer lifetimes gained for oncological patients due to their less invasive nature and the significantly reduced time expenditure required for this more flexible form of administration. As a result, the oncological patients will have more time to follow their own personal interests. It is to be expected that this will lead to a more flexible time management for hospitals and the treating physicians. Ultimately, the subcutaneous form of administration will only become a real alternative when it does not lead to markedly higher health-care costs for the society. This needs to be carefully examined by means of correctly and appropriately performed pharmaco-economic trials. It should also be mentioned that there will still be patients and physicians who continue to favour the intravenous administration. For some patients the longer treatment times associated with the conventional intravenous administration of mabs also represent a more intensive health-care support and provide a greater sense of security for which they are prepared to accept the more invasive and longer treatments. Also the currently valid reimbursement regulations for the various forms of therapy may well provide a stimulus to favour use of the intravenous route over the subcutaneous administration.

\section{Conclusion}

$\nabla$

The present article provides an overview on the subcutaneous administration of monoclonal antibodies in oncological therapy and the associated challenges. Up to now the desires of oncological patients for less invasive and more flexible forms of administration have not been sufficiently considered. The example of trastuzumab for patients with HER2-positive breast cancer has demonstrated that the development of alternative subcutaneous administration forms for monoclonal antibodies with at least comparable efficacy and tolerability and concomitantly lower and more effective utilization of medical resources is certainly possible in principle.

\section{Conflict of Interest}

$\nabla$

The authors declare that within the past 3 years they have been active or received support as follows: $\mathrm{CJ}$ consultancy fees from Roche, travel expenses from Roche and Amgen; VM fees for consultations and expertise from Roche, lectures for Roche, Colene, Pierre Fabre, travel expenses from GBG Forschungs $\mathrm{GmbH}$; CM fees for the performance of contracted clinical studies from Roche; SH consultancy fees from Roche; BA fees for consultations, lectures and contracted clinical studies from Roche, travel expenses from Roche.

\section{References}

1 Website of the Deutschen Krebsgesellschaft. Brustkrebs - Erkrankungsverlauf. Online: www.krebsgesellschaft.de; last access: 15.10.2013

2 Faderl S, Ferrajoli A, Wierda Wet al. Alemtuzumab by continuous intravenous infusion followed by subcutaneous injection plus rituximab in the treatment of patients with chronic lymphocytic leukemia recurrence. Cancer 2010; 116: 2360-2365

3 Hale G, Rebello P, Brettman LR et al. Blood concentrations of alemtuzumab and antiglobulin responses in patients with chronic lymphocytic leukemia after intravenous or subcutaneous routes of administration. Blood 2004; 104: 948-955

4 MabCampath Alemtuzumab, Zusammenfassung des EPAR für die Öffentlichkeit. Online: http://www.ema.europa.eu/docs/de_DE/ document_library/EPAR___Summary_for_the_public/human/000353/ WC500025261.pdf; last access: 04.12.2013

5 Aue G, Lindorfer MA, Beum PV et al. Fractionated subcutaneous rituximab is well-tolerated and preserves CD20 expression on tumor cells in patients with chronic lymphocytic leukemia. Haematologica 2010; 95: 329-332

6 Davies A, Merli F, Mihaljevic B et al. Pharmacokinetics, safety, and overall response rate achieved with subcutaneous administration of rituximab in combination with chemotherapy were comparable with those achieved with intravenous administration in patients with follicular lymphoma in the first-line setting: stage 1 results of the phase $3 \mathrm{SAB}-$ RINA study (BO22334). Blood (ASH Annual Meeting Abstracts) 2012; 120: 1629

7 Pressemitteilung F. Hoffmann-La Roche Ltd. vom 2. September 2013

8 Stopeck AT, Lipton A, Body JJ et al. Denosumab compared with zoledronic acid for the treatment of bone metastases in patients with advanced breast cancer: a randomized, double-blind study. J Clin Oncol 2010; 28: 5132-5139

9 Fizazi K, Carducci M, Smith M et al. Denosumab versus zoledronic acid for treatment of bone metastases in men with castration-resistant prostate cancer: a randomised, double-blind study. Lancet 2011; 377: 813-822

10 Henry DH, Costa L, Goldwasser F et al. Randomized, double-blind study of denosumab versus zoledronic acid in the treatment of bone metastases in patients with advanced cancer (excluding breast and prostate cancer) or multiple myeloma. J Clin Oncol 2011; 29: 1125-1132

11 Smith MR, Saad F, Coleman R et al. Denosumab and bone-metastasisfree survival in men with castration-resistant prostate cancer: results of a phase 3, randomised, placebo-controlled trial. Lancet 2012; 379: 39-46

12 DKG. Interdisziplinäre S3-Leitlinie für die Diagnostik, Therapie und Nachsorge des Mammakarzinoms. Langversion 3.0, Aktualisierung 2012. Online: http://www.krebsgesellschaft.de/download/S3_ Brustkrebs_Update_2012_OL_Langversion.pdf

13 AGO Empfehlungen für die Diagnostik und Therapie von Patientinnen mit primärem und metastasiertem Brustkrebs, Version 2012.1D. Online: http://www.ago-online.de

14 Cardoso F, Harbeck N, Fallowfield L et al. Locally recurrent or metastatic breast cancer: ESMO Clinical Practice Guidelines for diagnosis, treatment and follow-up. Ann Oncol 2012; 23: vi11-vi19

15 Dahabreh IJ, Linardou H, Siannis F et al. Trastuzumab in the adjuvant treatment of early-stage breast cancer: a systematic review and metaanalysis of randomized controlled trials. Oncologist 2008; 13: 620-630

16 Harris CA, Ward RL, Dobbins A et al. The efficacy of HER2-targeted agents in metastatic breast cancer: a meta-analysis. Ann Oncol 2011; 22: $1308-1317$ 
17 Slamon DJ, Leyland-Jones B, Shak $S$ et al. Use of chemotherapy plus a monoclonal antibody against HER2 for metastatic breast cancer that overexpresses HER2. N Engl J Med 2001; 344: 783-792

18 Valero V, Forbes J, Pegram MD et al. Multicenter phase III randomized trial comparing docetaxel and trastuzumab with docetaxel, carboplatin, and trastuzumab as first-line chemotherapy for patients with HER2-gene-amplified metastatic breast cancer (BCIRG 007 study): two highly active therapeutic regimens. J Clin Oncol 2011; 29: 149156

19 Wardley AM, Pivot X, Morales-Vasquez F. Randomized phase II trial of first-line trastuzumab plus docetaxel and capecitabine compared with trastuzumab plus docetaxel in HER2-positive metastatic breast cancer. J Clin Oncol 2010; 28: 976-983

20 Fachinformation Herceptin ${ }^{\circledR}$, Fassung vom Januar 2013

$21 \mathrm{Xgeva}^{\circledR}$, Zusammenfasung der Merkmale des Arzneimittels, Fassung vom 11.09.2012. Online: http://www.ema.europa.eu/ema/index.jsp? curl=pages/includes/document/document_detail.jsp?webContent Id=WC500110381\&mid=WC0b01ac058009a3dc

22 Bittner B, Richter WF, Hourcade-Potelleret F et al. Development of a subcutaneous formulation for trastuzumab - nonclinical and clinical bridging approach to the approved intravenous dosing regimen. Arzneimittelforschung 2012; 62: 401-409

23 Haller $F$. Converting intravenous dosing to subcutaneous dosing with recombinant human hyaluronidase. Pharm Tech 2007; 10: 861 -864

24 Watson D. Hyaluronidase. Br J Anaesth 1993; 71: 422-425

25 Bookbinder LH, Hofer A, Haller MF et al. A recombinant human enzyme for enhanced interstitial transport of therapeutics. J Control Release 2006; 114: 230-241

26 Frost GI. Recombinant human hyaluronidase (rHuPH20): an enabling platform for subcutaneous drug and fluid administration. Expert Opin Drug Deliv 2007; 4: 427-440
27 Wynne C, Harvey V, Schwabe C et al. Comparison of subcutaneous and intravenous administration of trastuzumab: A phase I/Ib trial in healthy male volunteers and patients with HER2-positive breast cancer. J Clin Pharmacol 2013; 53: 192-201

28 Pegram M, Hsu S, Lewis G et al. Inhibitory effects of combinations of HER-2/neu antibody and chemotherapeutic agents used for treatment of human breast cancers. Oncogene 1999; 18: 2241 - 2251

29 Hourcade-Poterellet F, Lemenuel-Diot A, McIntyre C et al. Use of a population pharmacokinetic approach for the clinical development of a fixed-dose subcutaneous formulation of trastuzumab. CPT Pharmacometrics Syst Pharmacol 2014; 3: e87

30 Ismael G, Hegg R, Muehlbauer $S$ et al. Subcutaneous versus intravenous administration of (neo)adjuvant trastuzumab in patients with HER2positive, clinical stage I-III breast cancer (HannaH study): a phase 3 , open-label, multicentre, randomised trial. Lancet Oncol 2012; 13 : 869-878

31 Melichar B, Stroyakovskiy D, Ahn JN et al. Pathological complete response to trastuzumab subcutaneous fixed-dose formulation in the HannaH study: Subgroup analysis of patient demographics and tumor characteristics and influence of body weight and serum trough concentration of trastuzumab. Präsentiert als Poster auf dem ESMO-Kongress in Wien 2012

32 Pivot X, Gligorov J, Müller V et al. Preference for subcutaneous or intravenous administration of trastuzumab in patients with HER2-positive early breast cancer (PrefHer): an open-label randomised study. Lancet Oncol 2013; 14: 962-970

33 De Cock E, Semiglazov V, Lopez-Vivanco G et al. Time savings with trastuzumab subcutaneous vs. intravenous administration: a time-andmotion study. Präsentiert als Poster auf der International Breast Cancer Conference St. Gallen 2013, Abstract P209, 2013 